\title{
tPA use for Stroke in the Registry of the Canadian Stroke Network
}

\author{
Janel O. Nadeau, Steven Shi, Jiming Fang, Moira K. Kapral, Janice A. Richards, \\ Frank L. Silver, Michael D. Hill on behalf of the investigators for the Registry of \\ the Canadian Stroke Network
}

\begin{abstract}
Background: Thrombolytic therapy with recombinant tissue plasminogen activator (tPA) has been shown to be costeffective and safe. Thrombolysis for stroke with tPA is now a standard of care in North America. However, it is only used on a small percentage of patients. Methods: The Registry of the Canadian Stroke Network was a consent-based stroke registry from 21 hospital sites across Canada. Using the thrombolysis data in phase 1 and 2 of the Registry, we sought to describe the use of stroke thrombolysis and its outcomes. Results: A total of 4107 patients were diagnosed with ischemic stroke in phase 1 and 2 of the Registry, of which $8.9 \%$ were treated with tPA. In consented tPA patients, the method of tPA administration was $85.8 \%$ IV only, 9.0\% IA only, and 5.2\% IV/IA combined. Patients had a median onset-to-treatment time of 167 minutes [IQR 140-188]. One quarter (25.5\%) of eligible candidates (time from onset $<150$ minutes) were treated with tPA. Protocol violations occurred in 27.7\% (67/242) of patients with 14.9\% (10/67) mortality. Overall, in-hospital mortality was $11.6 \%$. Lower Canadian Neurological Scale score and higher glucose level were predictive of mortality The symptomatic intracerebral hemorrhage (ICH) rate (phase 2 only) was $4.3 \%$. The mean Stroke Impact Scale-16 score at six months was 73.2, approximately equivalent to a modified Rankin scale score of 2. Conclusions: At selected hospitals in Canada, thrombolysis use is higher than previously reported rates. Thrombolysis continues to be safe and effective in Canada.
\end{abstract}

RÉSUMÉ: Utilisation du rtPA dans le traitement de l'accident vasculaire cérébral selon le registre du Réseau canadien contre les accidents cérébro-vasculaires. Contexte: La démonstration est faite que la thrombolyse au moyen de l'activateur du plasmagène tissulaire recombinant (rtPA) est rentable et sûre. La thrombolyse par le tPA pour traiter l'accident vasculaire cérébral (AVC) fait maintenant partie du traitement standard en Amérique du Nord. Cependant ce traitement n'est administré qu'à un petit nombre de patients. Méthodes: Le registre du Réseau canadien contre les accidents cérébro-vasculaires est un registre avec consentement de patients provenant de 21 hôpitaux canadiens. Au moyen des données sur la thrombolyse pendant les phases 1 et 2 du registre, nous décrivons l'utilisation de la thrombolyse dans l'AVC ainsi que les résultats de ce traitement. Résultats: 4107 patients ont reçu un diagnostic d'AVC ischémique pendant les phases 1 et 2 du registre, dont 8,9\% ont été traités par le rtPA. Parmi les patients qui ont donné leur consentement, le mode d'administration du rtPA était par voie IV seule chez 85,8\%, par voie IA seule chez $9,0 \%$ et par voie IV et IA combinées chez 5,2\%. Le délai médian entre le début de l'AVC et le traitement était de 167 minutes (intervalle interquartile de 140 à 188 minutes). Le quart des patients éligibles (25,5\%), c'est à dire ceux chez qui moins de 150 minutes s'étaient écoulées depuis le début de l'AVC ont reçu du rtPA. Des dérogations au protocole sont survenues chez 27,7\% des patients (67/242) avec une mortalité de 14,9\% (10/67). Au total, la mortalité hospitalière était de $11,6 \%$. Un score plus bas à l'Échelle neurologique canadienne et un taux plus élevé de glucose étaient les deux marqueurs prédisant la mortalité. Le taux hémorragie intracérébrale symptomatique était de 4,3\% (phase 2 seulement). Le score moyen au stroke impact Scale-16 six mois plus tard était de 73,2, ce qui est à peu près équivalent à un score de 2 à l'échelle modifiée de Rankin. Conclusions: Le taux de thrombolyse est plus élevé que rapporté antérieurement dans certains centres hospitaliers canadiens. La thrombolyse demeure un traitement sûr et efficace au Canada.

Can. J. Neurol. Sci. 2005; 32: 433-439

Thrombolysis has revolutionized the treatment of acute ischemic stroke (AIS). Stroke is a leading cause of death and the principal cause of adult disability in Canada, ${ }^{1}$ and because AIS is the most common form of stroke, effective treatment is essential. Clinical trials and community practice have shown that thrombolysis with recombinant tissue plasminogen activator (tPA) improves ischemic stroke outcome if administered within three hours of stroke onset. ${ }^{2-4}$ Thrombolytic therapy with tPA is cost-effective and safe..$^{5-, 9}$

Intravenous tPA was conditionally licensed for use in Canada in February $1999,{ }^{10}$ following approval in the United States in
1996. The Standard Treatment with Alteplase to Reverse Stroke study subsequently demonstrated that treatment was effective. ${ }^{11}$ The Canadian Activase for Stroke Effectiveness Study has

From the Calgary Stroke Program, Department of Clinical Neurosciences, University of Calgary, Calgary, Alberta, Canada.

RECEIVED APRIL 5, 2005. ACCEPTED IN FINAL FORM MAY 27, 2005.

Reprint requests to: Michael D. Hill, Calgary Stroke Program, Department of Clinical Neurosciences, University of Calgary, Foothills Hospital, Rm 1242A, 1403 29th Street NW, Calgary, Alberta, Canada T2N 2T9 
similarly confirmed that stroke treatment with tPA is effective in community practice in Canada. ${ }^{12,13}$

Roughly 40,000 Canadians have an ischemic stroke each year and less than 6\% get treated with tPA.,14-16 This low percentage is partially because of the strict inclusion criteria required for administration of tPA, particularly the short time window, and partly because of lack of protocols and processes to expedite acute stroke care. Because the public may not recognize stroke symptoms, ${ }^{17,18}$ measures are being taken to improve awareness and rapid response. ${ }^{19,20}$

Symptomatic intracerebral hemorrhage (ICH) is the most devastating of the complications associated with use of tPA for AIS. Hemorrhage rates are highest when the protocol is not followed $^{21}$ and drop dramatically when thrombolysis is given strictly within the recommended therapeutic window, and when no contraindications are present. ${ }^{22,23}$

Since licensure of tPA, changes in practice have occurred. In this paper, we summarize current data on the safety and effectiveness of stroke thrombolysis from phases 1 and 2 of the Registry of the Canadian Stroke Network (RCSN).

\section{METHODS}

The RCSN is a comprehensive, prospective registry of consecutive stroke patients from across Canada, established in order to provide a picture of stroke care in the nation. The registry contains detailed records ranging from baseline to outcome information. The RCSN has been divided into three phases, of which phase 1 (June 2001 to February 2002) and phase 2 (June 2002 to December 2002) are analyzed in this study. Data were collected for all stroke types, from stroke centres in eight provinces (21 hospitals in phase 1, 25 in phase 2 ), with an estimated $20 \%$ of all stroke care in the country being provided at these institutions. ${ }^{24}$ The first two phases in the registry were limited to about $40 \%$ of the eligible patients, as signed informed consent was required. ${ }^{25}$

Data were extracted from the RCSN phase 1 and 2 for all patients presenting with AIS treated with tPA. Patients with transient ischemic attack, subarachnoid hemorrhage or intracerebral hemorrhage were excluded. Demographics, clinical data including the administration of tPA, process measures, and outcome were analyzed. Protocol violations were defined as use of tPA in the presence of suspected subarachnoid hemorrhage, INR $>1.7$, blood pressure $>185 / 110$, non-ischemic stroke, PTT $>40$, glucose $<3$ or $>22 \mathrm{mM}$, platelet count less than $100 \mathrm{x}$ $10^{9}$ cells per litre, seizure at onset, and symptom onset to hospital arrival time greater than three hours. We used three measures of baseline stroke severity: the Glasgow Coma Scale; the Canadian Neurological Scale (CNS); and the National Institutes of Health Stroke Scale (NIHSS). Secondary symptomatic ICH was defined by the appearance of hemorrhage on the second imaging scan plus neurological worsening.

The primary outcomes were in-hospital mortality, symptomatic ICH and Stroke Impact Scale-16 (SIS-16) at sixmonths. ${ }^{26,27}$ A good outcome was defined as a score $\geq 75$ on the SIS-16, meaning high physical function with a slight disability. ${ }^{26}$ Secondary outcomes included interval times, discharge disposition, the presence of a neurological deficit at discharge, length of hospitalization, and in-hospital complications. Complications such as cardiac arrest, myocardial infarction, decubitis ulcer, deep vein thrombosis, pneumonia, pulmonary embolism, urinary tract infection, falls, and depression were grouped as non-neurological complications.

\section{Statistical Methods}

The data are reported using standard descriptive statistics. Appropriate parametric (t-test) or non-parametric (MannWhitney-U, Kruskal-Wallis) tests were applied depending upon the distribution of each particular variable. Proportions were compared using a Chi-square test. Logistic regression provided adjusted estimates for binary outcomes. General linear modeling was used to estimate predictors of outcome on the SIS-16 scale. All multivariable models were developed using a backwards elimination procedure and the threshold significance level to keep a variable was 0.10. Analyses were performed using SAS 8.2.

\section{RESULTS}

\section{Description of the Cohort}

A total of 6091 patients were diagnosed with stroke in phase 1 and 2 of the RCSN, of which $4107(67.4 \%)$ had ischemic stroke. Of these, $366(8.9 \%)$ were treated with tPA. More patients were given tPA in phase $2(10.2 \%)$ than in phase 1 (7.9\%). Ultimately, $242(66.1 \%)$ patients provided informed consent to full participation in the RCSN, with detailed baseline data collection and six month follow-up interviews; for the remainder of patients, only a minimal data set could be collected. There was no difference in age, gender, median CNS score, level of consciousness, stroke subtype, median time intervals or length of hospitalization between patients who did not consent compared to consented patients. However, patients who did not consent were more likely to have more severe stroke $(75.0 \%$ vs. $70.9 \%$ with CNS score $\leq 7, \mathrm{p}=0.045$ ) and were more likely to die in hospital $(21.3 \%$ vs. $11.6 \%, \mathrm{p}=0.018) .{ }^{25}$ In-hospital mortality among all patients who received tPA, regardless of consent, was $14.6 \%$. For clarity's sake, we will not discuss unconsented tPA patients further.

\section{Baseline Characteristics}

Patients who were given tPA had a median age of 71. [Table 1]. Male sex (58.7\%), right-handedness $(71.8 \%)$ and Caucasian race $(87.9 \%)$ were predominant. Hypertension was the dominant risk factor and half of the patients had a clinical total anterior circulation syndrome. A large majority $(85.8 \%)$ of patients were treated with intravenous (IV) tPA. The median dose of tPA given was 63mg (IQR 53.5-72.5) for IV patients, and 20mg (IQR 7-50) for intra-arterial (IA) patients.

\section{Process Measures}

Only $66.9 \%$ of patients treated with tPA had a code stroke protocol activated, meaning a stroke emergency was declared by the paramedics. This warranted prompt communication with and transportation to a hospital with stroke care resources to determine if the patient was a candidate for an acute stroke intervention using standard orders [Table 2]. There was no difference in the last-seen-normal-to-emergency room (ER) median time between tPA patients in phases 1 (71, IQR 49-125 minutes) and 2 (78, IQR 50-133 minutes). Patients had a median 
Table 1: Baseline characteristics of AIS patients treated with tPA

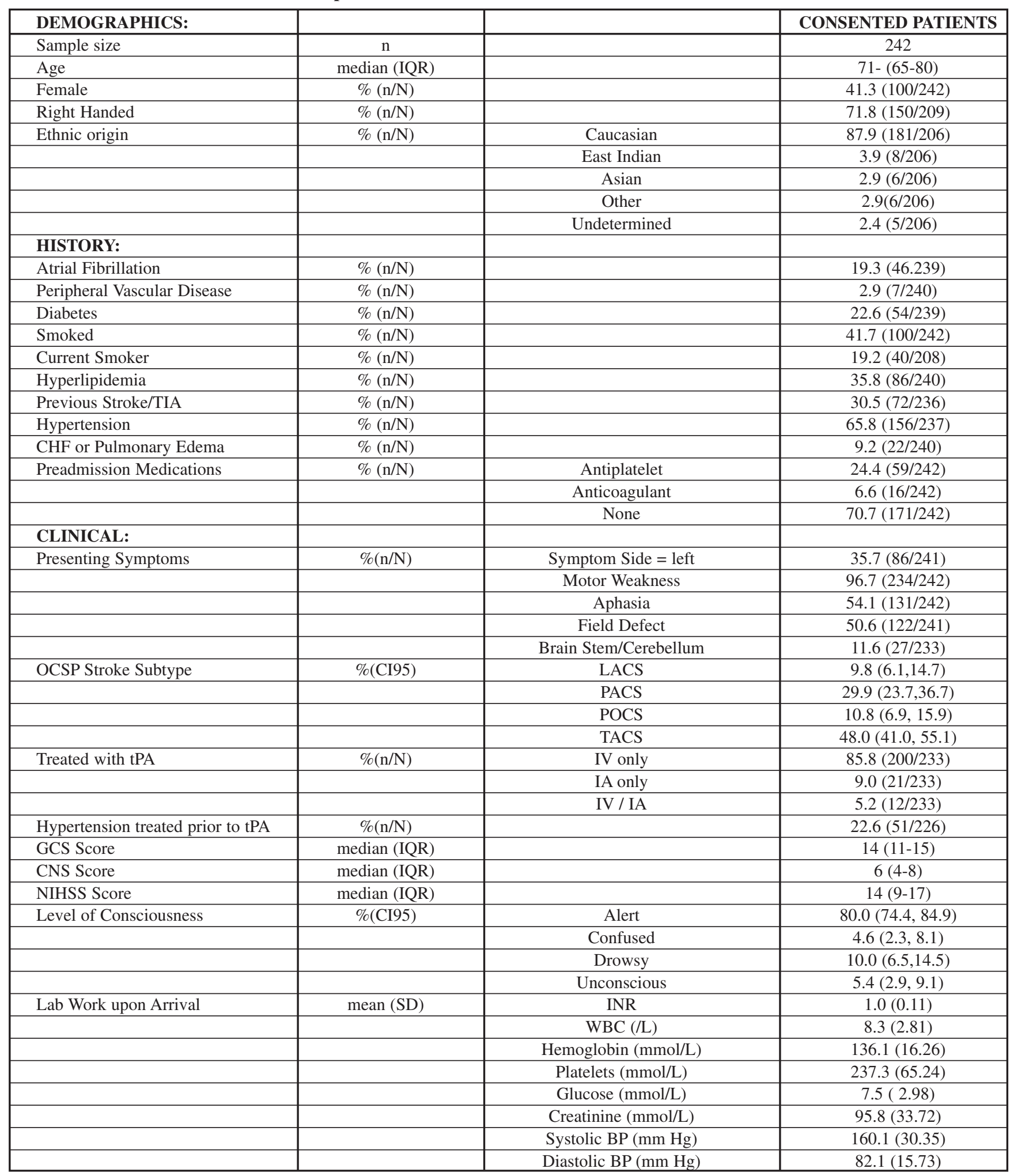

TIA, transient ischemic attack; CHF, congestive heart failure; OCSP, Oxfordshire Community Stroke Project; LACS, lacunar syndrome; PACS, partial anterior circulation syndrome; POCS, posterior circulation syndrome; TACS, total anterior circulation syndrome; tPA, tissue plasminogen activator; IV, intravenous; IA, intra-arterial; GCS, Glasgow Outcome Score; CNS, Canadian Neurological Score; NIHSS, National Institutes of Health Stroke Scale; INR, International Normalized Ratio; WBC, white blood count; BP, blood pressure. 
Table 2: Process measures of AIS patients treated with tPA in the RCSN

\begin{tabular}{|l|c|c|c|}
\hline VARIABLES: & & & CONSENTED PATIENTS \\
\hline Code Stroke Protocol Activated & $\%(\mathrm{n} / \mathrm{N})$ & & $66.9(162 / 242)$ \\
\hline Arrived from other Hospital & $\%(\mathrm{n} / \mathrm{N})$ & & $2.1(5 / 240)$ \\
\hline Transported by Ambulance & $\%(\mathrm{n} / \mathrm{N})$ & & $89.5(213 / 238)$ \\
\hline Hospital Type & $\%(\mathrm{n} / \mathrm{N})$ & Stroke Centre & $96.3(233 / 232)$ \\
\hline & & Community Hospital & $3.7(9 / 242)$ \\
\hline Patient Admitted to & $\%(\mathrm{n} / \mathrm{N})$ & Stroke Unit & $11.4(26 / 229)$ \\
\hline & & Neurology/Neurosurgery Ward & $15.3(35 / 229)$ \\
\hline & & ICU & $35.4(41 / 229)$ \\
\hline & & Step-down Unit & $10.9(25 / 229)$ \\
\hline & & Other & $9.2(21 / 229)$ \\
\hline Time Intervals & & Onset-to-ED time & $74.0(49-130)$ \\
\hline & & ED-to-CT time & $38.0(23-64)$ \\
\hline & & CT-to-treatment time & $46.3(27-77)$ \\
\hline Median Length of Hospitalization & days (IQR) & Total (Onset-to-treatment) & $166.6(140-188)$ \\
\hline
\end{tabular}

ICU, intensive care unit; ER, emergency room; CT, computed tomography; AIS, acute ischemic stroke; tPA, tissue plasminogen activator.

stroke onset-to-treatment time of 167 minutes, and $96.3 \%$ were treated in a hospital defined as a RCSN stroke centre. The rest of patients were initially transferred from a non-RCSN hospital. There were $28.3 \%(60 / 212)$ of patients that received treatment within one hour from ER arrival. A minority (35.4\%) received care in an intensive care unit, and only $11.4 \%$ received care in a stroke unit. Care in a stroke unit or teaching hospital were not predictors of mortality even after adjustment for stroke severity. Median duration of hospital stay was 11 days (IQR 5-21).

There was a significant inverse relationship between lastseen-normal-to-ER time versus ER-to-treatment time $(\mathrm{p}<0.0001)$

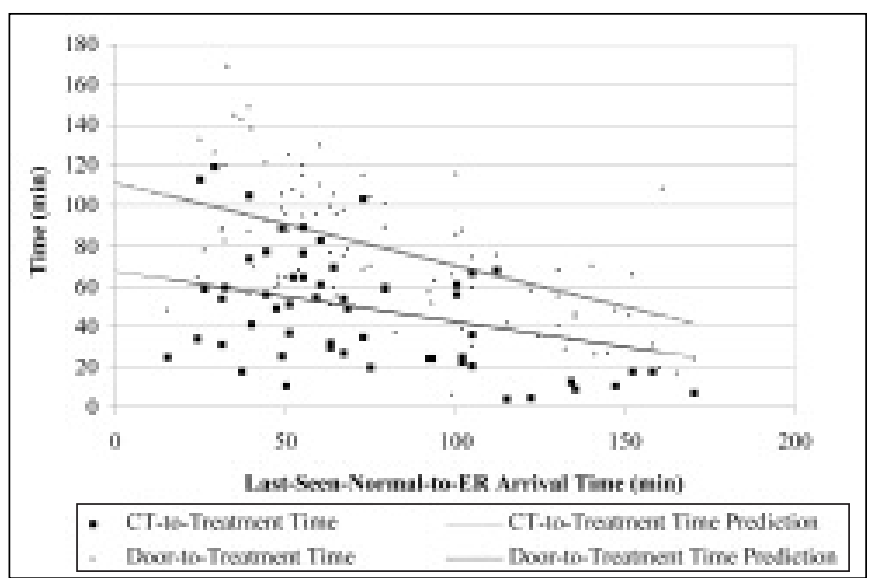

Figure: Relationship of last-seen-normal-to-ER arrival versus treatment time. Patients who arrived at the emergency department quicker after stroke onset typically had longer CT-to-tPA treatment times and subsequently longer ER-to-treatment times. The p-value was $<0.0001$. $E R$, emergency room; min, minutes; CT, computed tomography; tPA, tissue plasminogen activator.
[Figure]. This was driven by the computed tomography (CT)-totreatment time $(\mathrm{p}<0.0001)$, and not ER-to-CT time $(\mathrm{p}=0.415)$ and stroke severity did not confound this relationship. The Pearson correlation coefficients between time points are: lastseen-normal-to-ER and ER-to-treatment $\mathrm{r}=-0.39 \quad(\mathrm{p}<0.0001$, $\mathrm{n}=121$ ); last-seen-normal-to-ER and CT-to-treatment $\mathrm{r}=-0.32$ $(\mathrm{p}<0.0001, \mathrm{n}=121)$; CT-to-treatment and ER-to-treatment $=0.76$ $(\mathrm{p}<0.0001, \mathrm{n}=121)$.

Of all consented patients with AIS, 32.4\% (720/2220) were candidates for tPA based on time since stroke onset less than 150 minutes, yet only $25.5 \%$ (183/719) of these candidates received thrombolysis. The most prominent reasons for no treatment were that the deficit was deemed too mild in $196 / 536$ patients $(36.6 \%)$, and rapid improvement was observed in 161/536 patients $(30.0 \%)$. Of the AIS patients who did not arrive at the hospital

\section{Table 3: Protocol Violations of AIS patients treated with tPA.}

\begin{tabular}{|l|c|c|}
\hline PROTOCOL VIOLATIONS: & Total Patients & Deceased \\
\hline Total & 67 & $10 / 67$ \\
\hline Non-ischemic stroke & $5(7.5 \%)$ & $2 / 5$ \\
\hline Glucose $<3$ or $>22 \mathrm{mM}$ & $5(7.5 \%)$ & $4 / 5$ \\
\hline INR $>1.7$ & $0(0.0 \%)$ & 0 \\
\hline Platelet count $<100 \times 109$ cells/L & $1(1.5 \%)$ & $0 / 1$ \\
\hline Suspected SAH & $0(0.0 \%)$ & 0 \\
\hline Systolic blood pressure $>185$ & $37(55.2 \%)$ & $1 / 37$ \\
\hline Seizure at onset & $1(1.5 \%$ & $0 / 1$ \\
\hline$>3$ hours since onset & $24(35.8 \%)$ & $3 / 24$ \\
\hline
\end{tabular}

INR, International Normalized Ratio; SAH, subarachnoid hemorrhage. 
Table 4: Outcome of AIS patients treated with tPA in the RCSN

\begin{tabular}{|l|c|c|c|}
\hline VARIABLES: & & & CONSENTED PATIENTS \\
\hline Follow-up sample size & $\mathrm{n}$ & & 183 \\
\hline Neurological Deficit at Discharge & $\%(\mathrm{n} / \mathrm{N})$ & & $82.9(165 / 199)$ \\
\hline Complications at Discharge & $\%(\mathrm{CI} 95)$ & Non-CNS & $1.2(0,2.6)$ \\
\hline & & Seizure & $4.1(1.5,6.7)$ \\
\hline & & Symptomatic ICH $($ Phase 2 only) & $4.3(0.6,8.0)$ \\
\hline & & Fatal ICH & $0.9(0.0,2.5)$ \\
\hline Discharge Disposition & $\%(\mathrm{n} / \mathrm{N})$ & Acute Care & $12.8(26 / 203)$ \\
\hline & & I/P Rehab & $32.5(66 / 203)$ \\
\hline & & LT Care/Nursing Home & $6.4(13 / 203)$ \\
\hline & & Home & $43.4(88 / 203)$ \\
\hline In-Hospital Mortality & $\%(\mathrm{n} / \mathrm{N})$ & Other & $4.9(10 / 203)$ \\
\hline SIS-16 at 6 Months & Mean $(\mathrm{SD})$ & & $11.6(28 / 242)$ \\
\hline & $\%(\mathrm{n} / \mathrm{N})$ & $0-25$ & $73.2(29.5)$ \\
\hline & & $25-50$ & $14.1(20 / 142)$ \\
\hline & & $50-75$ & $16.9(24 / 142)$ \\
\hline
\end{tabular}

CNS, central nervous system; ICH, intracerebral hemorrhage; I/P, in-patient; LT, long term; SIS-16, Stroke Impact Scale 16.

within 150 minutes of stroke onset, $2.7 \%$ (41/1493) were thrombolysed. Among these 41 patients, 30 (73.2\%) were treated with IV tPA, nine $(22.0 \%)$ were treated intra-arterially (IA), one $(2.4 \%)$ was treated IV/IA and one patient did not have the method of tPA administration recorded. Protocol violations occurred in $27.7 \%(67 / 242)$ of patients who received tPA, with $14.9 \%(10 / 67)$ mortality [Table 3]. However, protocol violation was not associated with increased mortality or symptomatic ICH.

\section{Outcome}

In the subgroup of tPA patients in the RCSN, in-hospital mortality was $11.6 \%$. The CNS score (odds ratio $=0.68$ per unit increase, 95\%CI 0.54-0.85, $\mathrm{p}=0.001$ ) and glucose level (odds ratio $=1.24$ per mmol increase, 95\% CI 1.07-1.44, $\mathrm{p}=0.005$ ), but not age, gender or treatment time, were predictive of in-hospital mortality. At the time of discharge, $82.9 \%$ had a residual neurological deficit. In phase $2(\mathrm{n}=116)$, the symptomatic ICH rate was $4.3 \%$ (95\% CI: $0.6 \%-8.0 \%$ ) [Table 4 ].

Of the 242 consented tPA patients, 142 patients had their SIS16 scores recorded at six months, but the patients who were missing this data did not differ on baseline variables. The mean SIS-16 score was 73.2, and the percentage of patients having a score above 75 points was $62.0 \%$. In a multivariable model, age $(\mathrm{p}=0.013)$ and CNS score $(\mathrm{p}<0.001)$ were the only predictors of SIS-16. Outcome did not vary by onset-to-ER time or gender.

\section{Discussion}

Overall $8.9 \%$ of patients with AIS were treated with tPA in phase 1 and 2 of the RCSN. The proportion treated increased from phase 1 to phase 2 of the registry, which demonstrates an upward trend of acceptance of thrombolysis with time. This is higher than the international average, ${ }^{16,21,28,29}$ and suggests that at
RCSN hospitals stroke thrombolysis is becoming the accepted standard.

Of consented AIS patients in phase 1 and 2 of the RCSN, only $32.4 \%$ were candidates for tPA based on an onset-to-ER time less than 150 minutes, suggesting that the time from stroke onset to emergency arrival remains a very important barrier to thrombolysis delivery. Of these potentially eligible patients, only $25.5 \%$ were treated. So few patients were treated because the majority were considered too mild to warrant treatment or were improving rapidly. Patients with rapidly improving or mild symptoms warrant careful assessment because a third of such patients have poor outcomes. ${ }^{15}$

Intra-arterial (IA) and combined IV/IA therapies have been studied in acute stroke. ${ }^{30-32}$ In this cohort, tPA was given strictly IA $9.0 \%$ of the time, and $5.2 \%$ IV/IA. Despite the lack of efficacy trials, these alternate approaches are being put into practice in Canada.

Outcome of tPA patients is improved if treatment is initiated rapidly. The guideline endorsed by NINDS for ER-to-CT time is 25 minutes, and 60 minutes for ER-to-treatment time. ${ }^{33}$ In our study only $28.3 \%$ of patients were treated with an ER-totreatment time of less than 60 minutes. A significant negative relationship exists between last-seen-normal-to-ER arrival time and ER-to-treatment time. The patients received tPA much sooner after their CT scan if they arrived late in the time window. This has been previously reported, ${ }^{7,11}$ and indicates that patients arriving early to the ER are not receiving the benefits of expedited treatment.

Safety outcomes were consistent with results from the major randomized trials of tPA. ${ }^{2,11,12}$ There was a low reported symptomatic ICH rate among tPA patients of $4.3 \%$.

Patients in our study had a mean SIS-16 score of 73.2 points at six months, approximately equivalent to a modified Rankin 
scale score of $2 .{ }^{26}$ Predictors of SIS-16 were age and stroke severity. Gender was not a predictive factor. Women tend to do worse in the acute phase after stroke, with a longer hospital stay and more severe stroke. ${ }^{34-37}$ However, women who are treated with tPA for AIS benefit more than men $^{38}$ because treatment nullifies this sex-based difference. Since all patients were treated in our cohort, outcome (both mortality and SIS-16) did not differ by gender.

This study has notable limitations. There are comparatively few patients in this study $(n=242)$, in large part due to selection bias induced by the consent-based approach. ${ }^{25}$ This will not be an issue for the ongoing phase 3 of the RCSN as the Ethics Review Boards of the participating hospitals have permitted data collection without patient consent. Another limitation is that all data were from highly specialized institutions, ${ }^{24}$ which may have decreased mortality and improved outcome from the actual population. This implies that our results may not be fully generalizable to the average community hospital.

Stroke is an increasingly treatable illness, and with the advent of integrated "stroke teams" in Canada, stroke care is improving. Thrombolysis is a vital part of the system of stroke care and continues to be safe and effective in Canada.

\section{APPENDIX}

The following institutions participated in the Registry of the Canadian Stroke Network Phase I \& Phase II:

\section{Queen Elizabeth II Health Sciences Centre, Halifax, Nova} Scotia;

Saint John Regional Hospital, St. John, New Brunswick; Hôpital Notre-Dame du CHUM, Montreal, Quebec; Hôpital de l'Enfant-Jesus, Quebec City, Quebec; Hôpital Charles le Moyne, Greenfield Park, Quebec; Montreal General Hospital \& SMBD-Jewish General Hospital, Montreal, Quebec;

Sunnybrook \& Women's College Health Sciences Centre, Toronto, Ontario;

University Health Network/Toronto Western Hospital, Toronto, Ontario;

London Health Sciences Centre, London, Ontario;

The Ottawa Hospital, Ottawa, Ontario;

Kingston General Hospital, Kingston, Ontario;

Hamilton Health Sciences Centre, Hamilton, Ontario;

Trillium Health Sciences Centre, Mississauga, Ontario; Winnipeg Regional Health Authority, Winnipeg, Manitoba; Royal University Hospital, Saskatoon, Saskatchewan; Foothills Medical Centre, Calgary, Alberta;

University of Alberta Hospital, Edmonton, Alberta;

Lions Gate Hospital, North Vancouver, British Columbia;

Vancouver General Hospital, Vancouver, British Columbia; St. Paul's Hospital, Vancouver, British Columbia; Capital Health Region, Victoria, British Columbia; Thunder Bay Regional Hospital, Thunder Bay, Ontario; Hôpital Regional de Sudbury Regional Hospital, Sudbury Ontario;

North Bay General Hospital, North Bay, Ontario; Stratford General Hospital, Stratford, Ontario.

\section{REFERENCES}

1. Canadian Stroke Network Website. http://www.canadianstroke network.ca/aboutus/stroke101.php. Accessed January 19, 2005.

2. NINDS tPA Stroke Study Group. Tissue Plasminogen Activator for Acute Ischemic Stroke. New Eng J Med 1995;333:1581-1588.

3. Steiner T, Bluhmki E, Kaste M, et al. (ECASS Study Group). The ECASS 3-hour cohort: Secondary analysis of ECASS data by time stratification. European Cooperative Acute Stroke Study. Cerebrovasc Dis 1998;8:198-203.

4. Hacke W, Kaste M, Fieschi C, et al. Randomised double-blind placebo-controlled trial of thrombolytic therapy with intravenous alteplase in acute ischaemic stroke (ECASS II). Second European-Australasian Acute Stroke Study Investigators. Lancet 1998;352:1245-1251.

5. Chiu D, Krieger D, Villar-Cordova C, et al. Intravenous tissue plasminogen activator for acute ischemic stroke: feasibility, safety, and efficacy in the first year of clinical practice. Stroke 1998;29:18-22.

6. Graham GD. Tissue plasminogen activator for acute ischemic stroke in clinical practice: a meta-analysis of safety data. Stroke 2003;34:2847-2850.

7. Chapman KM, Woolfenden AR, Graeb D, et al. Intravenous tissue plasminogen activator for acute ischemic stroke: A Canadian hospital's experience. Stroke 2000;31:2920-2924.

8. Buchan AM, Barber PA, Newcommon N, et al. Effectiveness of tPA in acute ischemic stroke: outcome relates to appropriateness. Neurology 2000;54:679-684.

9. Sinclair SE, Frighetto L, Loewen PS, et al. Cost-Utility analysis of tissue plasminogen activator therapy for acute ischaemic stroke: a Canadian healthcare perspective. Pharmacoeconomics 2001;19:927-936.

10. Health Canada. Alteplase (Activase ${ }^{\circledR}$ rt-PA) for acute ischemic stroke: special precautions for new indication. Canadian Adverse Reaction Newsletter 1999;9:1-3.

11. Albers GW, Bates VE, Clark WM, et al. Intravenous tissue-type plasminogen activator for treatment of acute stroke: the Standard Treatment with Alteplase to Reverse Stroke (STARS) study. JAMA 2000;283:1145-1150.

12. Hill MD, Buchan AM and the CASES Investigators. Methodology for the Canadian Activase for Stroke Effectiveness Study (CASES). Can J Neurol Sci 2001;28:232-238.

13. CASES Investigators. The Canadian Alteplase for Stroke Effectiveness Study (CASES). CMAJ 2005; (in press).

14. Hill MD, Barber PA, Demchuk AM, et al. Building a "brain attack" team to administer thrombolytic therapy for acute ischemic stroke. CMAJ 2000;162:1589-1593.

15. Barber PA, Zhang J, Demchuk AM, Hill MD, Buchan AM. Why are stroke patients excluded from TPA therapy? An analysis of patient eligibility. Neurology 2001;56:1015-1020.

16. Wang DZ, Rose JA, Honings DS, Garwacki DJ, Milbrandt JC. Treating acute stroke patients with intravenous tPA. The OSF stroke network experience. Stroke 2000;31:77-81.

17. Kothari R, Sauerbeck L, Jauch E, et al. Patients' Awareness of Stroke Signs, Symptoms, and Risk Factors. Stroke 1997;28:1871-1875.

18. Pancioli AM, Broderick J, Kothari R, et al. Public perception of stroke warning signs and knowledge of potential risk factors. JAMA 1998;279:1288-1292.

19. Ovbiagele B, Saver JL, Fredieu A, et al. PROTECT: a coordinated stroke treatment program to prevent recurrent thromboembolic events. Neurology 2004;63:1217-1222.

20. United States Department of Health and Human Services. Healthy People 2010: Volume I (second edition) - Objectives for Improving Health, Focus Area 12. http://www.healthy people.gov/Document/HTML/Volume1/ 12Heart.htm. Accessed December 7, 2004.

21. Katzan IL, Furlan AJ, Lloyd LE, et al. Use of tissue-type plasminogen activator for acute ischemic stroke: the Cleveland area experience. JAMA 2000;283:1151-1158.

22. Bravata DM, Kim N, Concato J, Krumholz HM, Brass LM. Thrombolysis for acute stroke in routine clinical practice. Arch Intern Med 2002;162:1994-2001. 
23. Katzan IL, Hammer MD, Hixson ED, et al. Cleveland Clinic Health System Stroke Quality Improvement Team. Utilization of intravenous tissue plasminogen activator for acute ischemic stroke. Arch Neurol 2004;61:346-350.

24. Kapral MK, Laupacis A, Phillips SJ, et al. Investigators of the Registry of the Canadian Stroke Network. Stroke care delivery in institutions participating in the Registry of the Canadian Stroke Network. Stroke 2004;35:1756-1762.

25. Tu JV, Willison DJ, Silver FL, et al, for the Investigators in the Registry of the Canadian Stroke Network. Impracticability of Informed Consent in the Registry of the Canadian Stroke Network. N Engl J Med 2004;350:1414-1421.

26. Duncan PW, Lai SM, Bode RK, Perera S, DeRosa J. Stroke Impact Scale-16: A brief assessment of physical function. Neurology 2003;60:291-296.

27. Edwards B, O'Connell B. Internal consistency and validity of the Stroke Impact Scale 2.0 (SIS 2.0) and SIS-16 in an Australian sample. Qual Life Res 2003;12:1127-1135.

28. Grau AJ, Weimar C, Buggle F, et al. Risk factors, outcome, and treatment in subtypes of ischemic stroke: the German stroke data bank. Stroke 2001;32:2559-2566.

29. O'Connor RE, McGraw P, Edelsohn L. Thrombolytic therapy for acute ischemic stroke: why the majority of patients remain ineligible for treatment. Ann Emerg Med 1999;33:9-14.

30. Furlan A, Higashida R, Wechsler L, et al. Intra-arterial prourokinase for acute ischemic stroke. The PROACT II study: a randomized controlled trial. Prolyse in Acute Cerebral Thromboembolism. JAMA 1999;282:2003-2011.
31. IMS Study Investigators. Combined intravenous and intra-arterial recanalization for acute ischemic stroke: the Interventional Management of Stroke Study. Stroke 2004;35:904-911.

32. Lewandowski CA, Frankel M, Tomsick TA, et al. Combined intravenous and intra-arterial r-TPA versus intra-arterial therapy of acute ischemic stroke: Emergency Management of Stroke (EMS) Bridging Trial. Stroke 1999;30:2598-2605.

33. Marler JR, Jones PW, Emr P, (Eds). The National Institute of Neurological Disorders and Stroke. Proceedings of a National Symposium on Rapid Identification and Treatment of Acute Stroke. National Institutes of Health. Bethesda, Maryland. August 1997.

34. Roquer J, Campello AR, Gomis M. Sex differences in first-ever acute stroke. Stroke 2003;34:1581-1585.

35. Arboix A, Oliveres M, Garcia-Eroles L, et al. Acute cerebrovascular disease in women. Eur Neurol 2001;45:199-205.

36. Ayala C, Croft JB, Greenlund KJ, et al. Sex differences in US mortality rates for stroke and stroke subtypes by race/ethnicity and age, 1995 to 1998. Stroke 2002;33:1197-1201.

37. Wyller TB, Sodring KM, Sveen U, Ljunggren AE, Bautz-Holter E. Are there gender differences in functional outcome after stroke? Clin Rehabil 1997;11:171-179.

38. Kent DM, Price LL, Ringleb P, Hill MD, Selker HP. Sex-based differences in response to recombinant tissue plasminogen activator in acute ischemic stroke: a pooled analysis of randomized clinical trials. Stroke 2005;36:62-65. 